\title{
Marital status and gender as predictors of undergraduate academic performance: a United Arab Emirates context
}

\author{
Justin Thomas, Monique Raynor, Amal Al-Marzooqi \\ Zayed University, UAE
}

\section{Introduction}

There is a considerable international body of literature exploring the predictors and determinants of undergraduate academic performance (Barrow et al., 2009; Betts \& Morell, 1999; Cohn et al., 2004; Smith \& Naylor, 2001). The predictor variables explored encompass a full biopsychosocial spectrum, from familial socio-economic status, to institutional class sizes. Two of the most immediately accessible factors for exploration are gender and marital status. While these proposed predictors of academic performance have been widely explored across many nations, relatively little work has been undertaken within the Gulf region (Harb \& El-Shaarawi, 2007). It is likely that region-specific socio-cultural factors will affect how, and to what extent, gender and marital status influence academic performance. Given that many of the Gulf nations are presently attempting to develop knowledge based economies, such research may inform the development of undergraduate educational strategy and policy.

The small body of research within the Gulf region focusing on gender and marital status is fairly unequivocal. Using either cumulative grade point averages (CGPA), or specific course grades as indicators of performance, virtually all of the published studies report females as outperforming males. Hedjazi and Omidi (2008) found that amongst undergraduate agricultural students at the university of Tehran in Iran, female students significantly outperformed their male counterparts. Similarly, Harb and El-Shaarawi (2007) found that female undergraduates studying within the college of business and economics at UAE University, significantly outperformed their male colleagues. In Kuwait Al-Otaibi (1996) reports Kuwaiti females as having significantly higher scores on a measure of academic achievement motivation compared to Kuwaiti males, although this study is silent about actual academic performance. However, a more recent study undertaken in Kuwait, focusing on students at the Arab Open University (AOU), reports females as having higher CGPA's than males across the board (AlMutairi, 2010). Furthermore, Al-Khader (1996) reports the same pattern of findings amongst psychology students at Kuwait University, with females again outperforming males. Only one Gulf based study reports males as outperforming females, and this study was limited to focusing on the outcomes of a single introductory finance course (Al-Tamimi \& Al-Shayeb, 2002). One of the shared limitations of the above research, perhaps with the exception of Al-Mutairi (2010), is the reliance on relatively small samples and a restricted focus to specific academic disciplines, or even individual courses.

In terms of marital status several international studies report better performance for married undergraduates compared to their unmarried classmates. For example Smith \& Naylor (2001) explored the data for all students graduating from all UK universities in 1993. In their analysis married students (men and women) do better than unmarried students. There is little data on this issue in the Gulf region; however, Al-Mutairi (2010) reports married students at the AOU outperforming their unmarried counterparts, and concludes that marital status plays a significant role in determining students' performance.

Thomas, J., Raynor, M., \& Al-Marzooqi, A. (2012). Marital status and gender as predictors of undergraduate academic performance: a United Arab Emirates context. Learning and Teaching in Higher Education: Gulf 
Much of the work to date in exploring the predictive power of these demographic variables within Gulf populations has been based on relatively small samples, and limited to focusing on specific disciplines, or even individual course outcomes. The present study aims to explore both gender and marital status as determinants of academic performance across the entire student body of a large multi campus federal university in the UAE (Zayed University). This institution is almost exclusively attended by UAE citizens, and has campuses in both Dubai and Abu Dhabi. Based on previous research we hypothesise that females will have higher CGPA's than males, and that married students will have higher CGPA's than unmarried students.

\section{Methods}

Anonymized quantitative data were extracted from Zayed University's student information management system (as approved by Zayed University's Research Ethics Committee). The data extracted related to all students currently studying at undergraduate level within the institution. The data fields extracted were date of birth, gender, program of study, marital status and campus location (Dubai or Abu Dhabi). Overall the sample/extract comprised 3672 student records. In terms of gender, females accounted for $90.2 \%$ of the sample; for location, Abu Dhabi campus accounted for $50.5 \%$ of the sample; and for marital status $2.8 \%$ of students were recorded as being married. Students who were recorded as divorced $(0.1$ $\%, n=4)$ were excluded from the analyses.

The mean age of students was, 20.98 years $(S D=2.51)$, and there was a significant difference in age between male $(M=21.51, S D=4.43)$ and female $(M=20.93$., $S D=2.19)$ students: $t[377.34]=-2.46, p$ $<.02$. There was also a statistically significant difference in age between married $(M=27.54, S D=6.46)$ and unmarried $(M=20.71, S D=1.64)$ students: $t[100.38]=10.59, p<.001$. It is also worth noting that there was greater variability of ages within the male and married cohorts.

In addition to the data extract, a small number of married students were interviewed to get their perspectives on the relationship between marital status and academic experience. An opportunity sample of seven married students were interviewed: four males and three females. Their ages ranged from twenty-one to twenty-nine years old; all but one student had at least one child and one student had remarried. All of the female students and two of the male students were in a Majors program; the other two males were General Education students. Two of the men and one of the women were married prior to attending Zayed University, while the other four students married after commencing their studies. A semi-structured interview was undertaken; the key open-ended question was: "How do you feel being married affects your time at university?" Interviewees were subsequently prompted to consider both positive and negative factors.

\section{Results}

\section{Gender}

Figure 1 shows the mean CGPA's for male and female students. Looking at the whole sample, and statistically controlling for age, females $(M=2.64, S D=.58)$ had significantly higher GPA's than males $(\mathrm{M}=2.41, \mathrm{SD}=.71) \mathrm{F}[1,3539]=37.81, \mathrm{p}<.001$. However, given that the majority of males $(64.9 \%)$ are presently in the General Education program it made sense to look specifically at the CGPA gender effects in this narrower and more homogenous context. Females ( $M=2.47, S D=.65)$ again significantly outperformed males ( $\mathrm{M}=2.39, \mathrm{SD}=.79) \mathrm{F}[1,1728]=3.07, \mathrm{p} .<.05$. The next largest program for males was Information Systems and Technology Management (IT). This attracts $12 \%$ of all males, who

Thomas, J., Raynor, M., \& Al-Marzooqi, A. (2012). Marital status and gender as predictors of undergraduate academic performance: a United Arab Emirates context. Learning and Teaching in Higher Education: Gulf 
comprise $49.5 \%$ of the institution's IT students. Amongst the IT students there was no significant gender difference in CGPA.

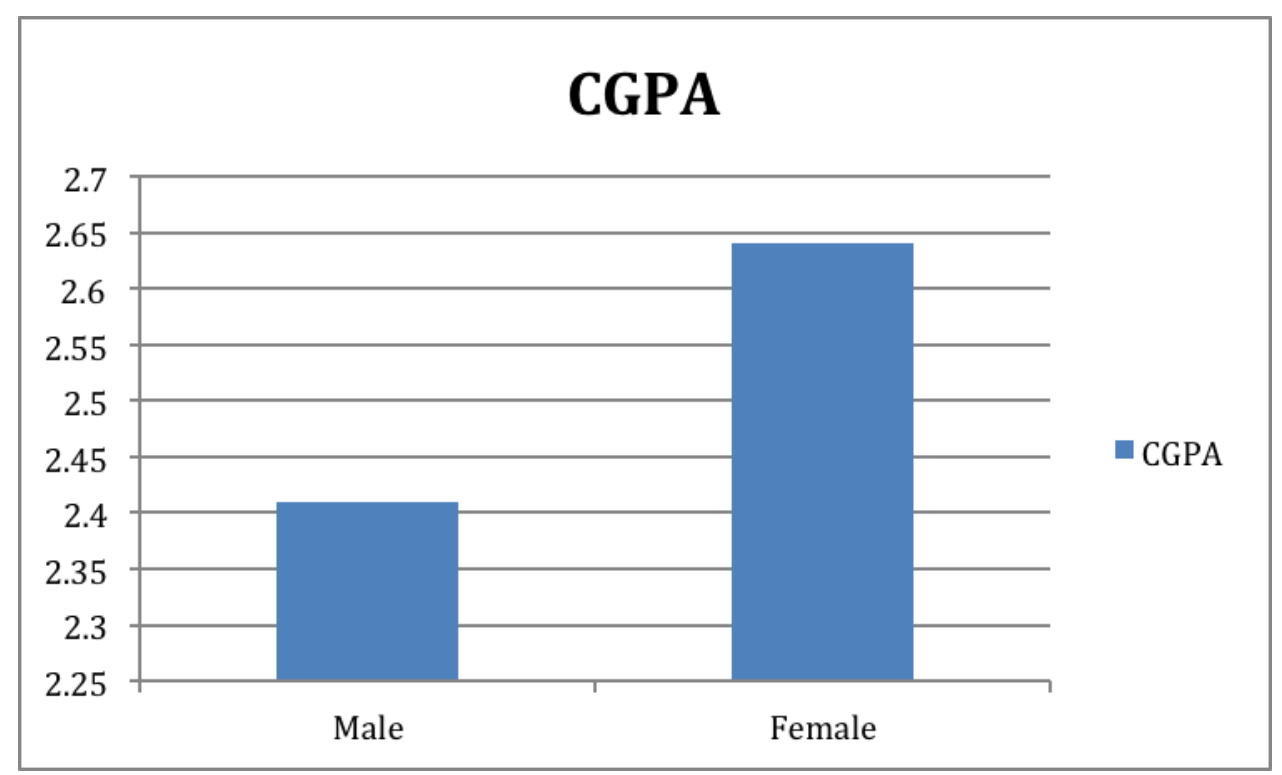

Figure 1: Mean difference in Cumulative Grade Point Averages between males and females (all majors including General Education students).

\section{Age}

Older males tended to have higher CGPA's than younger males: the correlation coefficient for males was $r=.17, p<.001$. For females there was no significant correlation; however, taking the sample as a whole, age showed a small but significant correlation with improved academic performance $r=.03, p<$ .05

\section{Marital Status}

Figure 2 shows the mean CGPA for married and unmarried students. Married students $(M=2.76, S D=$ $.64)$ had significantly higher CGPA's than their unmarried counterparts $(M=2.62, S D=.59), F[1,3538]=$ $5.58, p<.02$. However once we controlled for age (married students were significantly older) these effects were no longer statistically significant. The exact same pattern of results emerge when exploring the data for males and females separately. Similarly, when the analysis was restricted to mature students only (age > 26), mature married students, significantly outperformed mature unmarried students; however controlling for age again eliminated the statistical significance of this effect.

Thomas, J., Raynor, M., \& Al-Marzooqi, A. (2012). Marital status and gender as predictors of undergraduate academic performance: a United Arab Emirates context. Learning and Teaching in Higher Education: Gulf 


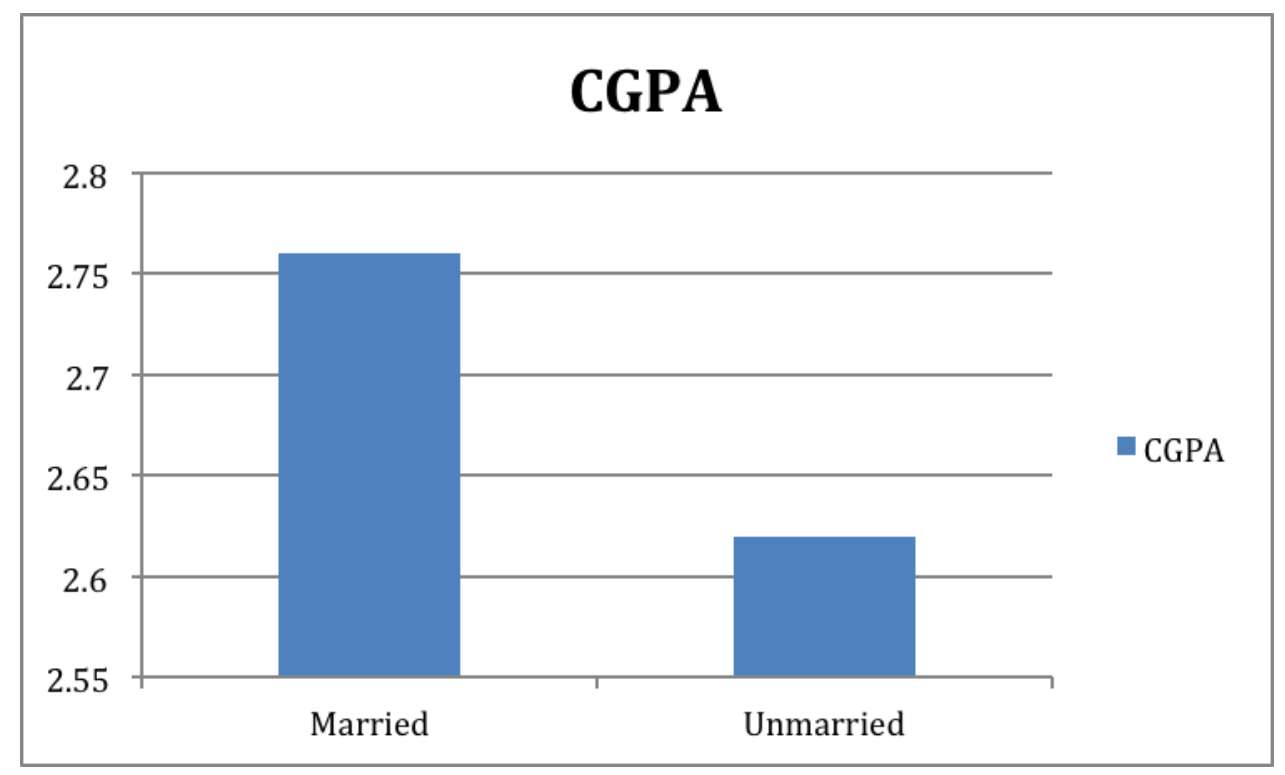

Figure 2: Mean difference in Cumulative Grade Point Averages between married and unmarried students (all majors including General Education students)

\section{Interviews}

From these interviews the following seven broad themes emerged.

\section{The need for focus, and role-management}

Cognizant of their multiple roles (husband, wife, mother, student, employee, etc.) the participants described having developed their own unique processes for managing these roles. Methods of selfmanagement discussed included: completing all work related to their studies on campus before returning home, since there were "less distractions at school", and allocating space in their homes for studying. There was lots of talk about setting aside time for children and spouses. For the two male students who were also working full-time, there were the additional challenges of the workplace that also had to be managed.

\section{Motivation and seriousness}

All of the students reported a marked increase in seriousness and focus towards their studies since getting married. Marriage and parenthood were reported as the motivating factor behind this change. Some reported an improvement in their academic performance: one student reported that after getting married and having her child her GPA improved; she believed that "having all of this responsibility forces [you] to have all of [your]... homework finished" so that you have time for your family and saw "all of the responsibilities as an advantage as they have made [her] more willing to do [her] work". Another student reported that prior to marriage she was "an average student... bored with [her] Major and wanted to quit" yet after getting married she realised that she needed to be more focused on her studies so that she could find work after graduation.

For the female students, the decision to continue with their studies after marriage was not an easy one to make. One of the students took a year off from her studies after getting married in order to have a child, before returning to her studies; the other female students interviewed returned to their studies immediately (or were married before university). The challenge for all of the women was managing their

Thomas, J., Raynor, M., \& Al-Marzooqi, A. (2012). Marital status and gender as predictors of undergraduate academic performance: a United Arab Emirates context. Learning and Teaching in Higher Education: Gulf 
husband's expectations of them with regards to child care and time spent with their spouse. To avoid discontent in the household, the students try to use their time between classes to complete assignments and readings required for classes so that their time at home can focus primarily on their children and their husbands. However, all of the females reported that while initially studying at home was a difficult adjustment for their husbands they are now more supportive of their studies and have support from their husbands and extended families.

Fatherhood and assuming the responsibility for the financial well-being of their families was the motivator for all of the male students to take their academic studies more seriously. Prior to marriage, they were not serious or as focused on their studies, attended classes sporadically and did not put a lot effort into completing their given assignments. However, after marriage this changed dramatically: in addition to the responsibility of being a husband and having a family to take care of, the men reported a level of maturity towards their studies that they did not observe amongst many of their unmarried peers (or in themselves prior to marriage). One of the male students reported that before he was married he would "come to school, go to class, leave school and not return home until [he needed] to sleep...there was no time for studying". Since getting married he "goes home after class, studies, has a room to study in and [his wife] will make sure that [he] has clean clothes and food", something, he reports, that was lacking prior to marriage.

\section{Expectations of their spouse}

While the male students reported fewer difficulties with managing their relationships with their spouse, all of the students admitted that relationship management, while studying, can be challenging. All of the female students reported that their husbands help them either with the children or with the household tasks or both, yet this was something that has developed over time: they were not as understanding at the initial stages of marriage towards their wife's studies. A female student stated that "most people think of Gulf men, UAE Emirati men, as [not being responsible] towards their children [and that] all of the responsibility is on the mother; [my husband] is understanding." Admittedly, maintaining the delicate balance between their studies and their spouse was challenging yet paramount to their academic success. One student reported that when she initially started her studies at Zayed University her husband would complain that her "studies were more important than him." The experience of being a wife and a student was best summarised as follows:

"If you are not married you are not sitting at university thinking about what you are going to have for lunch or dinner because someone else is taking care of that for you. When you are married you are the one thinking about these things."

\section{Parenthood}

For any new parent, tending to the needs of a child can be especially demanding on your time, particularly if it is your first child; couple parenthood with studying full-time and you have additional challenges, as reported by the students interviewed. Prior to the arrival of a baby sometimes complications with the pregnancy can develop. If you are studying and complications arise this can result in a student having to leave school and return after the birth of their child; while the time off is important it presents an academic strain on their return to university, as one student reported. In addition, the university allows for only one week maternity leave; as a result, the students reported that many women choose to take a year off from university in order to have more time with their children and ultimately many of these women decide not to return. Of the female students interviewed, one took a year off after having her child; another had her child during the summer and returned to university the following semester; and the remaining female student does not have children.

Thomas, J., Raynor, M., \& Al-Marzooqi, A. (2012). Marital status and gender as predictors of undergraduate academic performance: a United Arab Emirates context. Learning and Teaching in Higher Education: Gulf 
Support from one's spouse with child rearing is essential for academic success, as discussed above. Yet responsibility for the primary care of children still falls upon the mother, student or not. As one male student surmised "it depends on their mothers, how, because sometimes... I cannot sit with [my child] because he is noisy so his mother will take him [outside]... it is the relationship between the mother and [the child] that is... important".

While the expectations of parenthood have been discussed as a challenge, the students did not considered having children as a negative. Children were seen as "a blessing" and having "their attention makes [a parent] feel happy" as they help put their lives into perspective. One student reported that sometimes he has many things on his mind when he comes home "such as [his] job, [his] studies, but...[his son] will come over and kiss [him] and hug [him] and after that [he] feels that this relieves some of the pressure, stress on [him]".

\section{Expectations of the Extended Family}

Support from the extended family is appreciated when one parent is studying full-time. However, managing their expectations of the time that you spend with them can be challenging. This was primarily a difficulty discussed by the female students. For these married Emirati women, there is the expectation that they will spend time with her mother-in-law by accompanying her to weddings, cultural celebrations etc., and the option to decline attendance at these events does not exist. Thus, academic studies are a times sacrificed in order to meet the expectations of the extended family and "this is one of the pressures" that the female students face. While spending time with family and extended family was very important to all of the students interviewed, attending social events presented a dilemma for some of the students because you "could do... more things for university than going out... but you cannot say no". "You cannot put your studies before your families", especially when it comes to your mother-in-law.

\section{The expectations of work}

Being in a position to meet the financial expectations of married life was an important concern for all of the men interviewed. Two of the men worked full-time, one was on leave from his job until the successful completion of his studies and one student was not working. Work was important to both male and females students and having a good job that pays well was essential to all of them. For the male students, in particular, their expectations of work influenced their commitment to their academic studies since the successful completion of their studies would ensure attractive employment options, more opportunities for promotion and greater financial rewards; all factors that will benefit their families.

\section{Additional benefits as a result of married status}

Effective time management was viewed as integral to academic success. With the additional responsibilities of being a spouse and sometimes a parent in addition to a student all of the married students reported becoming more aware of, appreciative of and skilled in time management. These time management skills had helped them to be more focused in their studying and have propelled some of the female students into informal leadership positions in the classroom. While they did not attribute this solely to their marital status they did suggest that the skills developed in the management of their marital roles were advantageous to their academic performance. As a result, the women found they were better equipped to contribute to classroom discussions and manage their peers within group-work situations. They reported that unmarried students often deferred to them for academic advice and leadership.

Thomas, J., Raynor, M., \& Al-Marzooqi, A. (2012). Marital status and gender as predictors of undergraduate academic performance: a United Arab Emirates context. Learning and Teaching in Higher Education: Gulf 
The responsibilities of marriage propelled the students to a level of maturation that was noticeably advanced in comparison to their peers. As a result, people, teachers, colleagues, friends and family interact and respond to them in a more mature and adult manner. When comparing themselves to their peers who were not married, two of the males students commented that their maturity was a result "of marriage, [their] age and life experience", aspects that many of the younger male students had not yet encountered. For the women, this maturity was recognised as "the mother role", a position that their unmarried peers seek out when they encounter academic and personal problems and want someone to talk with.

There are many challenges that are faced by married students at Zayed University; yet the findings of the interviews suggest that while these challenges can present some difficulties they can be managed and in some cases can be advantageous to academic performance.

\section{Conclusion}

The present study focused on marital status and gender as determinants of academic performance amongst students attending a federal university in the UAE. The results support the growing body of regional studies reporting better academic performance amongst females. In the present study female undergraduates were generally younger than males; however, the effect of gender persisted even after controlling for age. The same pattern of findings was also observed when we narrowed the focus, exploring the academic performance of students presently in the General Education program. The only exception to females outperforming males was when we focused on the traditionally male-dominated discipline of information technology (Margolis \& Fisher, 2002). For IT students there were no gender differences in academic performance, although here one might hypothesise males doing better.

One explanation for this finding may be the relatively recent addition of male undergraduate programs. Zayed University at its inception in 1998 was a female only institution, significant enrollment of males only started in 2006, and some of the gender gap may be accounted for by the relative nascence of the male programs. However, this gender difference is reported in at least five other regional studies focusing on undergraduate performance, including one undertaken in the UAE (Harb \& El-Shaarawi, 2007). This gender difference certainly warrants further investigation within the Gulf context.

In terms of marital status the present findings are in line with those reported for Kuwaiti AOU students by Al-Mutairi (2010) and also the UK national findings reported by Smith and Naylor (2001). However neither of these studies controlled for age; married students tend to be older students, and age or relative maturity may be the more important determinant. In the present study this appeared to be the case, as the effect of marital status was greatly reduced once age was controlled for.

It is often suspected that marriage brings with it additional responsibilities and burdens which may hamper academic performance. It may be that the drop-out rate is higher amongst married students, making the married students who remain a particularly studious and resilient subgroup. Future studies exploring marital status and academic performance should also explore the relative rates of attrition. The present study, however, finds no support for the idea that marriage is detrimental to academic performance. In fact the qualitative interview data with married students identifies a number of themes centering on increased motivation and personal growth contributing to improved academic performance post-marriage.

The present study does have some important limitations; firstly, the findings are not generalizable to the broader context of UAE tertiary education: there is a great deal of heterogeneity amongst the tertiary

Thomas, J., Raynor, M., \& Al-Marzooqi, A. (2012). Marital status and gender as predictors of undergraduate academic performance: a United Arab Emirates context. Learning and Teaching in Higher Education: Gulf 
educational offerings in the UAE. That said, Zayed University produces a sizable proportion of the UAE's graduates, especially its female ones. A further limitation is the descriptive and correlational nature of the study. Although the sample was large, the number of married students is relatively small. While the number of married students was sufficient based upon power estimates, a larger pool of married students would increase our confidence in the representativeness of the mean GPA. cross-institutional data analysis might help here.

Future research should explore the possible causes of the apparent superior academic performance of females at the undergraduate level, exploring perhaps gender differences in lifestyle and aspirations. Having a deeper understanding of the factors underlying this gender asymmetry in terms of academic performance may help inform remedial initiatives and actions directed at improving the performance of male students. It would also be beneficial to attempt to explore the unreported numbers of young Emirati men who travel overseas for tertiary education. These men are generally unaccounted for, thus skewing the higher education attendance figures in favor of females (Luomi, 2008). This may also partially explain the GPA gap too, especially if it is the higher performing males who are completing tertiary education overseas. Similarly, future regional research could look at primary and secondary educational performance to identify the approximate stage of study that significant gender divergence becomes apparent. Undoubtedly more research is required if well considered, evidence based interventions are to be delivered.

\section{References}

Al-Khader. (1996). Factors affecting performance of psychology students at Kuwait University. The Educational Journal, 10(40), 141-169.

Al-Mutairi, A. (2010). Factors Affecting Business Students' Performance in Arab Open University: The Case of Kuwait. International Journal of Business Management, 6(5), 146 - 155.

Al-Otaibi. (1996). The effect of demographic variables on achievement motivation among Kuwaiti students at Kuwait university. Arab Journal of Administrative Sciences, 3(2), 339-364.

Al-Tamimi, H., \& Al-Shayeb, A. (2002). Factors affecting student performance in the introductory finance course. Journal of Economic \& Administrative Sciences, 18(2), 76-86.

Barrow, M., Reilly, B., \& Woodfield, R. (2009). The determinants of undergraduate degree performance: how important is gender? British Educational Research Journal, 35(4), 575-597.

Betts, R. J., \& Morell, D. (1999). The Determinants of Undergraduate Grade Point Average. Journal of Human Resources, 34(2), 268-293.

Cohn, E., Cohn, S., Balch, D. C., \& Bradley, J. (2004). Determinants of undergraduate GPA's: SAT scores, high-school GPA and high-school rank. Economics of Education Review, 23(6), 577-586.

Harb, N., \& El-Shaarawi, A. (2007). Factors affecting business students' performance: The case of the United Arab Emirates. Journal of Business Education, 82(5), 282-290.

Hedjazi, Y., \& Omidi, M. (2008). Factors affecting the academic the academic success of agricultural students at University of Tehran, Iran. Journal of Agricultural Science and Technology, 10, 205-214.

Luomi, M. (2008). Reforming Higher Education: the GCC highway in the shadow of the World Bank road. In C. Davidson \& P. M. Smith (Eds.), Higher Education in the Gulf States. London: SAQI in association with London Middle East Institute at SOAS.

Thomas, J., Raynor, M., \& Al-Marzooqi, A. (2012). Marital status and gender as predictors of undergraduate academic performance: a United Arab Emirates context. Learning and Teaching in Higher Education: Gulf 
Margolis, J. \& Fisher, A. Unlocking the clubhouse: women in computing. Cambridge, MA: MIT Press.

Smith, J., \& Naylor, R. (2001). Determinants of degree performance in UK universities: a statistical analysis of the 1993 cohort. Oxford Bulletin of Economics and Statistics, 63(1), 29-60.

Thomas, J., Raynor, M., \& Al-Marzooqi, A. (2012). Marital status and gender as predictors of undergraduate academic performance: a United Arab Emirates context. Learning and Teaching in Higher Education: Gulf 